\title{
Cursos organizados por módulos: uma proposta para o desenvolvimento das habilidades de leitura e escrita em nível superior
}

Carmem Luci da Costa Silva* Paula Ávila Nunes ${ }^{\star}$

\section{Resumo}

Este texto tem por objetivo refletir sobre uma alternativa para o ensino de leitura e produção textual em nível superior por meio de um curso organizado em módulos, no qual diferentes gêneros são trabalhados de forma a contribuir para o desenvolvimento e a consolidação das habilidades necessárias para a produção de textos da esfera acadêmica. $\mathrm{O}$ trabalho tem, ainda, a pretensão de suprir, parcialmente, a lacuna existente em termos de produção científica que tomam o ensino de texto e de língua portuguesa no ensino superior como objeto de estudo.

Palavras-chave: Texto. Ensino superior. Módulos. Gêneros.

\section{Introdução: situando a reflexão}

Ainda que a pesquisa sobre o ensino de leitura e de produção textual em nível superior seja verdadeiramente escassa no Brasil, a realidade que se apresenta aos professores universitá-

\footnotetext{
Doutora em Letras pela Universidade Federal do Rio Grande do Sul, é professora de Língua Portuguesa na mesma instituição, onde atua na graduação em Letras e no respectivo Programa de Pós-Graduação, na linha de pesquisa de Teorias do Texto e do Discurso. E, também, coordenadora do Programa de Apoio à Graduação (PAG2) na área de Língua Portuguesa. E-mail: clcostasilva@hotmail.com.

* Doutora em Letras pela Universidade Federal do Rio Grande do Sul, é professora de Língua Portuguesa e Linguística da Universidade Tecnológica Federal do Paraná, onde atua no ensino técnico, superior e em pós-graduação lato sensu, ministrando aulas tanto no curso de Letras quanto naqueles em que a Língua Portuguesa é parte integrante do currículo. E-mail: paulaavilan@gmail.com.
}

Data de submissão: fev. 2013 - Data de aceite: abr. 2013 http://dx.doi.org/10.5335/rdes.v9i1.3534 
rios deixa claro o descompasso que há entre o que se espera, em termos de proficiência linguística, e o que é de fato apresentado por esses alunos, tanto em nível de graduação como, até mesmo, em pós-graduação. E, para tratar do desenvolvimento das habilidades de falar, de escutar, de ler e de escrever na universidade, é necessário que se leve em conta os contextos anteriores de ensino-aprendizagem em que o aluno esteve imerso: os níveis fundamental e médio. Ou seja, há uma história de relação com a língua e com textos que esse aluno carrega e que tem reverberações em sua escrita na universidade.

Quando as pesquisas produzidas por uma linguística centrada no uso da língua começaram a proliferar, após a década de 1980, no Brasil, surgiram, no cenário de ensino de língua materna, críticas acerca da sua finalidade e dos conteúdos selecionados para a aprendizagem. Entre as críticas mais frequentes ao ensino de língua portuguesa dito tradicional, destacavam-se: a desconsideração de atividades de uso da língua; o uso do texto como pretexto para ensinar valores morais e para o tratamento de aspectos gramaticais; a excessiva valorização da norma linguística, marcada pela primazia a regras de exceção; o ensino descontextualizado, com ênfase na metalinguagem, normalmente vinculado à memorização de terminologias e associado à identificação de fragmentos em frases soltas; e a apresentação de uma teoria gramatical, sem a devida reflexão do funcionamento da língua em seus vários níveis (fonológico, morfológico, sintático e semântico). E, de fato, esse é o ensino a que muitos, quiçá a maioria, de nossos alunos foram expostos durante seu período escolar, sendo essa a "herança" que levam ao ensino superior.

A partir de todas essas críticas e da constatação da falta de proficiência que esse tipo de trabalho com texto gerava, produziu-se um pressuposto consensual acerca do ensino de língua portuguesa de que as práticas precisavam partir do uso (linguagem) para permitir a conquista de novas habilidades linguísticas (metalinguagem). É justamente levando em conta tal pressuposto que os Parâmetros Curriculares Nacionais (PCNs) defendem, como objetivo do ensino de língua materna, o desenvolvimento da competência discursiva do aluno. Por isso, nessa nova diretriz, o texto, em toda a sua diversidade de gêneros, passa a ser o objeto de ensino. Além de se partir da língua em uso, os PCNs consideram a importância de se tomar a língua como objeto de reflexão, a fim de possibilitar ao aluno produzir categorias explicativas acerca de seu funcionamento, não na forma de memorização de nomenclaturas, mas de entendimento da sistemática e do funcionamento teórico e empírico do texto.

Com isso, as noções de interlocução e de significação ganham relevo na produção, na leitura e na escuta de textos vinculados à situação de uso. Segundo tal concepção, desenvolver a proficiência 
do aluno em sua língua materna equivale a capacitá-lo para, nas diversas trocas sociais, produzir textos adequados aos variados contextos de interlocução, o que origina diferentes efeitos de sentido. É nessa diretriz que encontramos a seguinte tese nos PCNEM: "Quando se dialoga com alguém ou se lê um texto, é pela interlocução que se constroem os sentidos; também é nela que os interlocutores se constituem e são constituídos" (2002, p. 61).

Nessa linha de reflexão, o desenvolvimento e aprimoramento dos três níveis de competência (interativa, gramatical e textual) são entendidos como pressupostos necessários à constituição do sujeito falante e escrevente de uma língua, tornando necessário o trabalho com as habilidades de falar, escutar, ler e escrever. Em contrapartida, parece-nos que a dificuldade de lidar, nos níveis fundamental e médio, com essas três competências, essenciais na relação de ensino-aprendizagem de leitura e de produção de textos, faz que o aluno apresente-se na universidade com um uso de língua distante do requerido nesse contexto em que dele é exigido produção de conhecimento que somente pode ocorrer por meio da língua em uso.

É nesse cenário de urgência de disciplinas e cursos que proporcionem aos alunos de ensino superior condições de aprimoramento, principalmente das competências de leitura e de escrita que os cursos de Letras são chamados a apoiar os discentes dos diferentes cursos da universidade que tiveram um percurso de, pelo menos, onze anos de ensino de língua portuguesa. Dialogando com essa tendência, citamos como exemplo o Programa de Apoio à Graduação (PAG), criado na Universidade Federal do Rio Grande do Sul, onde é desenvolvido desde 2010. O PAG, um projeto acadêmico proposto pela Pró-Reitoria de Graduação, com apoio da Pró-Reitoria de Pós-Graduação da UFRGS, no âmbito do Programa Reuni, tem por objetivo a qualificação da graduação. Um dos projetos vinculados ao Programa é o PAG 2 , cujo objetivo é apoiar estudantes que necessitem de reforço no processo de ensino-aprendizagem em determinadas áreas, entre elas, língua portuguesa, com ênfase em aspectos de leitura e de produção de textos da esfera acadêmica. A proposta visa a proporcionar, além da sala de aula, novas oportunidades de ensino-aprendizagem, planejadas e executadas por uma equipe que envolve desde alunos da graduação a pós-doutorandos, coordenados por um professor da área. ${ }^{1}$

A implementação do Programa deixou claro, desde seu início, que há, tal como aludimos anteriormente, franca disparidade entre os conhecimentos esperados e efetivamente apresentados pelos alunos de ensino superior. Tal diferença entre expectativa e realidade pode ser observada, entre tantos outros indicadores, por meio da quantidade significativa de alunos que buscam no Programa de Apoio à Graduação (PAG2) subsídios para suprir a falta que encontram em seus cursos de 
graduação, fato que se estende, inclusive, a pós-graduandos, motivo pelo qual o PAG2-Projeto Língua Portuguesa foi inserido, em 2010, como apoio à graduação e, em 2011, passou a apoiar, também, discentes de pós-graduação.

A procura pelo apoio em língua portuguesa na graduação e as solicitações de apoio à pós-graduação encaminham-nos a pensar nos motivos que produzem essa demanda. Uma das razões do sucesso do Projeto de Língua Portuguesa no âmbito do PAG2 reside, em nosso entendimento, na forma diferenciada pela qual o curso leva o trabalho com texto para seus alunos. Certamente, tal diferenciação não reside apenas na estruturação em módulos, divididos de acordo com diferentes gêneros textuais, visto que tal prática encontra respaldo, inclusive, em importantes documentos que, ainda que não se refiram especificamente ao ensino em nível superior, são basilares para nortear aspectos de ensino em nível nacional e regional: os Parâmetros Curriculares Nacionais e os Referenciais Curriculares do RS.

O diferencial desse curso parece estar, antes, em sua capacidade de utilização dessa forma de estruturação para levar aos alunos um tratamento com texto que tem por objetivo central o desenvolvimento das competências leitora e escritora, voltadas, especificamente, para os gêneros da esfera acadêmica, objetivo que, apesar de trivial, é de difícil operacionalização para o discente. Chamamos de "trivial" pelo simples fato de que o desenvolvimento dessas competências deveria ser objeto de trabalho do professor de língua portuguesa desde o ensino fundamental. No entanto, o que se observa é que, ao ingressar em um curso superior, os alunos não só não tiveram tal preparação como também - e mais importante - não a encontram na universidade nas matrizes curriculares de seus cursos.

Nessa conjuntura, este texto tem por objetivo responder aos seguintes questionamentos: 1) tendo como ponto de partida a língua em uso, como trabalhar em sala de aula com o texto?; 2) a partir de determinadas concepções sobre linguagem, como fazer a transposição didática de teorias para trabalhar com texto e proporcionar ao aluno familiaridade com esse objeto para que desenvolva suas habilidades de ler e de escrever?

Para tanto, este escrito organiza-se em duas grandes seções. A primeira delas, a seguir, relata e discute as concepções teóricas que embasam o trabalho pedagógico do curso que utilizamos como exemplo para ilustrar nossa alternativa para o trabalho com texto em nível superior. Nessa seção, destacamos, sobretudo, a concepção de hibridismo discursivo como constitutivo dos gêneros, ideário que sustenta a proposta de trabalho com textos que será aqui ilustrada. $\mathrm{Na}$ segunda parte, são discutidas as noções de gêneros do discurso (BAKHTIN, 1979/2003) e de sequências didáticas (DOLZ; NOVERRAZ; SCHNEUWLY, 2010) que embasam a organização do 
curso em módulos, exemplificando como concebemos a possibilidade de organização de um curso que desenvolva as habilidades de leitura e de escrita ancorado em um entendimento de língua como atividade discursiva, sempre instanciada no tempo e no espaço e produto da interação entre interlocutores.

\section{O hibridismo dos gêneros do discurso em sala de aula: a proposta do trabalho em módulos no contexto universitário}

O aluno que ingressa no sistema universitário passa por uma prova de língua portuguesa e de redação que o autoriza a prosseguir em um percurso institucionalizado de produção de conhecimento. A constante reclamação de professores universitários de diferentes áreas acerca da leitura e das produções de textos realizadas por seus alunos, somada à busca de "apoio" de muitos universitários nos cursos de Letras para que tenham auxílio em seus processos de análises textuais e de escrita, leva-nos a pensar no papel da língua portuguesa no contexto do ensino superior.

Sabemos que o mundo acadêmico exige produção de conhecimento por meio da elaboração de textos de gêneros distintos (resumos, resenhas, monografias, ensaios, artigos etc.) para as diferentes disciplinas que o aluno cursa. Caso seja graduando e esteja envolvido na inicia- ção científica, torna-se necessário que divulgue os resultados de sua pesquisa e, caso seja pós-graduando, a exigência de divulgação de seu fazer científico aumenta: é necessário que publique artigos regularmente, e, principalmente, que elabore dissertação (mestrando) e tese (doutorando). Essa exigência também é atestada por Motta-Roth e Hendges, ao pontuarem que

[...] no sistema universitário brasileiro, a política de financiamento de bolsas de iniciação científica, de bolsas de pós-graduação e de projetos de pesquisa se baseia no conhecido ditado "Publique ou pereça!" (Publish or perish!) das universidades americanas. Essa pressão para escrever e publicar tem levado alunos, professores e pesquisadores universitários a um esforço concentrado na elaboração de textos de qualidade na forma de artigos para periódicos acadêmicos e livros para editoras como meio de assegurar um espaço profissional. Desse modo, na cultura acadêmica, a produtividade intelectual é medida pela produtividade na publicação (2010, p. 13).

O presente item deste texto apresenta uma reflexão acerca do lugar que ocupam os programas de apoio ao discente universitário de diferentes níveis nessa "cultura acadêmica de produtividade intelectual". Temos claro que, para apresentar o exemplo de organização de um programa que busca "reforçar" os alunos no uso de sua língua materna, os pontos de ancoragem das atividades propostas são muitos e, consequentemente, não redutíveis a um quadro teórico único de referência. Entretanto, há que se definir um ponto de vista que seja transversal para o desenvolvimento do trabalho, 
mesmo que esse ponto de vista advenha de diferentes abordagens que, por não se contradizerem naquilo que consideramos fundamental, complementam-se. Assim, concebemos, como princípio unificador da proposta de ensino aqui apresentada, a intersubjetividade como constitutiva da linguagem, que pode ser desdobrado em um axioma importante para se pensar o ensino de leitura e de escrita: $a$ interlocução é inerente à língua em uso. Esses princípios fundamentam-se em reflexões de três grandes mestres da linguagem, de cuja obra destacamos apenas algumas passagens:

[...] todo falante é por si mesmo um respondente em maior ou menor grau: porque ele não é o primeiro falante, o primeiro a ter violado o eterno silêncio do universo, e pressupõe não só a existência do sistema da língua que usa, mas também de alguns enunciados antecedentes - dos seus e alheios - com os quais o seu enunciado entra nessas ou naquelas relações (baseia-se neles, polemiza com eles, simplesmente os pressupõe já conhecidos do ouvinte). Cada enunciado é um elo na corrente organizada de outros enunciados (BAKHTIN, 1979/2003, p. 272).

****

Não atingimos nunca o homem separado da linguagem e não o vemos nunca inventando-a. Não atingimos jamais o homem reduzido a si mesmo e procurando conceber a existência do outro. É um homem falando que encontramos no mundo, um homem falando com outro homem, e a linguagem ensina a própria definição de homem (BENVENISTE, 1966/1995, p. 285).

$* * *$

Considerar a comunicação como função linguística fundamental é admitir que a fala, por vocação natural, é fala para outrem, e que a própria língua não se realiza senão quando fornece um lugar de encontro para os indivíduos (DUCROT, 1972, p. 9).
Benveniste, ao afirmar que o homem nasce na cultura, e não na natureza, defende que o sistema cultural é o elemento responsável por atribuir o que tem e o que não tem sentido e, principalmente, por definir um sistema de valores que, segundo ele, a língua carrega como uma herança. Nesse caso, há valores inerentes à vida social (BENVENISTE, 1974/1989, p. 22) e é dessa ordem do herdado que também Bakhtin () concebe os gêneros do discurso: "Esses gêneros do discurso nos são dados quase da mesma forma que nos é dada a língua materna...” (1979/2003 , p. 282).

Como todo mecanismo da cultura possui um caráter simbólico (BENVENISTE, 1974/1989), a apropriação da língua e a sua conversão em discurso estão necessariamente ligadas ao conjunto de valores que cada língua materna traduz, tradução que delimita justamente o que tem sentido. A entrada do sujeito falante em novas situações de convívio com a linguagem, pela necessidade que tem de tornar significativos seus usos linguísticos, requer o diálogo com certa "herança" na busca de novas maneiras de se relacionar com a língua - falada e escrita - e com o outro. Trata-se da necessidade de domínio de modos de dizer e de escrever nas diferentes situações de uso da língua, questão corroborada por Bakhtin:

Quanto melhor dominamos os gêneros tanto mais livremente os empregamos, tanto mais plena e nitidamente descobrimos neles a nossa individualidade (onde isso é possível e necessário), refletimos de modo mais flexível e sutil da situação singular da comunicação; em suma, realizamos de modo mais acabado o nosso livre projeto de discurso (1979/2003, p. 285). 
É essa busca de liberdade e de autonomia de empregos da língua que encaminha os discentes a procurarem "apoio" para escrever e ler textos. Nesse cenário, quem está sendo solicitado a apoiar precisa propor atividades para que o aluno simbolize novas situações de uso da língua que o permitam inserir-se, conforme palavras de Bakhtin (1979/2003), no "elo da cadeia discursiva" do mundo acadêmico, que carrega relações valorativas para cada gênero de discurso.

Seguindo o pensamento benvenistiano de que é o símbolo que estabelece o elo entre os homens, a língua e a cultura, entendemos que, em qualquer nível de ensino, trata-se de letrar e de oralizar, na busca de simbolização dos diferentes atos de enunciação, concebidos como a conversão da língua em discurso (BENVENISTE, 1974/1989, p. 83), para que o aluno se insira na "corrente discursiva" de produção intelectual. É no meio desse caminho que o professor tem papel fundamental para a produção de práticas significativas em sala de aula, desde a criação de contextos funcionais de uso da língua, com propostas que convoquem o aluno a enunciar-se, seja oralmente, seja por escrito, até a análise significativa e criteriosa das produções que lhe oportunizem refletir sobre a sua produção para que, com base nessa reflexão sobre o seu fazer na e com a linguagem e sob a condição de intersubjetividade, constitua diálogos entre parceiros em produções que sejam singulares e, ao mesmo tempo, constituam laços com outros dizeres ins- critos em sua vida social, principalmente com os dizeres da esfera discursiva da qual faz parte: a comunidade acadêmica. Isso porque "as palavras podem entrar no nosso discurso a partir de enunciações individuais alheias, mantendo em menor ou maior grau os tons e ecos dessas enunciações individuais" (BAKHTIN, 1979/2003, p. 293).

Como o homem está imerso na linguagem e na cultura com outros desde sempre, consequentemente, estabelece relações de sentido e de valoração que lhe permitem ser constituído pela língua e constituí-la em suas diferentes modalidades nas distintas instâncias culturais em que se insere. É nesse sentido que o PAG, desenvolvido no âmbito do "Projeto de Língua Portuguesa: leitura e produção de textos”, proposta ilustrada neste artigo, concebe o entrelaçamento entre as quatro habilidades de uso da língua (falar, ouvir, ler e escrever), vinculadas ao pressuposto de que "todo homem inventa sua língua e a inventa durante toda sua vida" (BENVENISTE, 1974/1989, p. 18), para ancorar a produção de conhecimento na universidade como relacionada a empregos anteriores da língua em outros discursos e como possibilidade de criar novos empregos em distintas situações de uso.

Qual a tarefa do professor que concebe o discurso, produto da enunciação, como um elo na cadeia discursiva? Como o professor pode desenvolver um trabalho que vincula o discurso a outros precedentes e, ao mesmo tempo, valoriza 
uma atitude inventiva diante de cada produção do aluno? Se, de um lado, o professor leva em conta que há algo de repetível (há uma história de cada gênero na cultura acadêmica) que precisa recuperar com o aluno, de outro, torna-se necessário incitá-lo a criar novos modos de dizer e de escrever a partir da análise e da reflexão de discursos anteriores em relação com o discurso atual desse aluno. Nesse ponto, consideramos fundamental a integração dos processos de ler e de escrever em sala de aula. Com certeza, as inquietações dos estudantes no que diz respeito a essa relação entre o velho e novo são muitas e, entre essas inquietações, alguns vilões aparecem: os modelos que lhe foram inculcados; uma concepção de texto centrada em tipologias canônicas (textos narrativos, descritivos, dissertativos etc.), considerados como puros; e a separação texto/ gramática, quando a língua é colocada em funcionamento na produção de discurso, com a desconsideração de que as formas da gramática são meios para se produzir sentidos nos textos.

Para lidar com esses "vilões", os discentes universitários passam a compartilhar noções fundamentais acerca de texto que sustentam as atividades, dentre as quais destacamos a de que não há tipos textuais puros e que estes são atualizados em gêneros de discurso, que, por sua vez, são híbridos, tanto em termos tipológicos quanto em termos de gêneros. A partir dessas noções, a proposta organiza-se em módulos em que os gêneros acadêmicos são colocados em diálogo para que constituam um "elo na cadeia discursiva" de sala de aula. Esse "elo" é proposto a partir dos seguintes princípios metodológicos: 1) há imbricação entre os gêneros acadêmicos; 2) a imbricação dos gêneros requer que se leve em conta a complexidade gradual envolvida nos modos de integração de um em outro; e 3) há histórias na e com a linguagem que o aluno universitário carrega. Tais princípios serão aprofundados na segunda parte deste texto.

É nesse sentido que, para lidar com a mescla de tipo e a heterogeneidade de gêneros, ancoramos o desenvolvimento das atividades com os seguintes suportes teóricos: 1) com a noção de sequências tipológicas de Adam (2008), para tratar da mescla de sequências nos gêneros (ex.: tratamento de artigo científico com integração de sequências descritivas, narrativas etc., mas com predomínio da argumentativa); e 2) com a concepção de que há heterogeneidade entre gêneros, caso da monografia, que mescla resumo e resenha no referencial teórico.

As concepções que elencamos abaixo são compartilhadas com os alunos com base na reflexão desenvolvida por Marcuschi (2002) no texto "Gêneros textuais: definição e funcionalidade", que se constitui em alavanca para os módulos que sequenciam o trabalho:

- Um texto é uma estrutura tipologicamente heterogênea porque os diferentes tipos textuais (descrição, narração, explicação, injunção e argumentação) mesclam-se para 
constituir a unidade textual. Cada passagem de diferente tipo constitui uma determinada sequência tipológica.

- A unidade textual é garantida por meio da constituição de uma dominante sequencial (ex.: domínio da argumentação sobre a narração no gênero artigo científico). A dominante sequencial permite a classificação de um texto como dissertativo, narrativo, descritivo, expositivo etc. Além disso, constituir a tessitura das diferentes sequências é uma das habilidades necessárias para escrever um texto coeso.

- Todo tipo textual é materializado em algum gênero textual (crônica, resenha, artigo, ensaio etc.); assim, a interlocução somente é possível por meio de algum gênero textual.

- Os gêneros:

- são os textos com os quais nos deparamos na vida diária. Constituem textos empiricamente realizados que cumprem funções nas diferentes situações comunicativas e nas distintas esferas de atividades humanas;

- não são entidades naturais, mas artefatos culturais construídos historicamente. Surgem devido às necessidades e às atividades socioculturais, bem como vinculados às inovações tecnológicas;

- Enquanto os tipos são contáveis (narração, descrição, injunção, exposição e argumentação), os gêneros são ilimitados (videoconferência, teleconferência, e-mails, bate-papo virtual, cardápio, ser- mão, telefonema, horóscopo, receita, artigo científico, edital de concurso, ensaio, resenha, resumo, monografia, dissertação, tese, bula de remédio, carta comercial, ata, relatório...);

- Os gêneros da esfera acadêmica são híbridos. Por exemplo, uma dissertação de mestrado mescla os gêneros resumo e resenha.

Dados os fundamentos, passemos a discutir outros dois conceitos centrais para o desenvolvimento do programa nos moldes que propomos: o de gêneros do discurso e o de sequência didática.

\section{As noções de gêneros de discurso e as sequências didáticas para o
ensino de texto}

O trabalho com gêneros do discurso, na forma que Bakhtin (1979/1992, p. 279) entende o termo (a saber, "tipos relativamente estáveis de enunciados"), não é mais novidade no cenário educacional brasileiro, sobretudo diante da ampla divulgação que lhe deram os PCNs e as diretrizes regionais de ensino. Na esteira dessa noção, surgem teóricos dedicados a refletir sobre a operacionalização do trabalho com gêneros do discurso em sala de aula, representados, especialmente, pelas figuras de Bernard Schneuwly e Joaquim Dolz. A organização do curso de apoio, objeto destas páginas, está fortemente ancorada no trabalho desses teóricos, ainda que não os siga pari passu. 
Por essa razão, tornam-se necessárias algumas explicações sobre como entendemos a relação das propostas bakhtinianas com o ensino e sobre a forma como as contribuições das releituras de sua obra, feitas pelos teóricos supracitados, influenciam nosso trabalho pedagógico.

Inicialmente, é necessário observar que a noção de sequência didática, elaborada por Dolz, Noverraz e Schneuwly, tem por objetivo, entre outros aspectos, estabelecer um programa de ensino que satisfaça, nas palavras dos autores, as seguintes exigências (entre outras):

Permitir o ensino da oralidade e da escrita a partir de um encaminhamento, a um só tempo, semelhante e diferenciado; [...] centrar-se, de fato, nas dimensões textuais da expressão oral e escrita [e] [...] oferecer um material rico em textos de referência, escritos e orais, nos quais os alunos possam inspirar-se para suas produções (2004, p. 81).

Estando pautado em teorias que consideram a língua como um produto social, renovado a cada vez pelo uso que o sujeito faz dela (cf. BENVENISTE, 1974/1989; DUCROT, 1972), a concepção de ensino idealizada pelos autores, ao dar prioridade para um ensino ao mesmo tempo semelhante e diferenciado, está em completa consonância com nossa linha teórica de concepção de linguagem. Ao seguir o raciocínio de Benveniste, o qual postula que "todo homem inventa sua língua e a inventa durante toda sua vida. $\mathrm{E}$ todos os homens inventam sua própria língua a cada instante e cada um de uma maneira distintiva, e a cada vez de uma maneira nova" (1974/1989, p. 18), o objetivo do ensino de leitura e de produção textual passa a ser, em nosso entendimento, justamente o de tornar diferenciado aquilo que é semelhante. Expliquemos: ao organizarmos o curso em módulos, conforme antecipado na primeira parte deste texto, damos, de um lado, prioridade ao aspecto da repetibilidade intrínseca ao gênero, o que Bakhtin chama de "características mais ou menos estáveis", que antecipam o que pode ou não ser escrito e a forma como esse escrito deve ou não ser lido. Entretanto, de outro lado, a tarefa do professor de produção reside em possibilitar aos alunos que, dentro dessa estabilidade, possa haver subjetividade, já que, como tão bem lembra Marcuschi, "para Bakhtin era mais importante frisar o relativamente do que o estável" (2002, p. 18, grifos do autor).

No meio acadêmico, em particular, há extrema relutância, por parte de alunos de alguns cursos, de romper com o cânone de escrita de determinado gênero. Desse ponto de vista, os gêneros deixam de ser estruturas relativamente estáveis e passam a ser "camisas de força", uma espécie de fórmula, universal, que deve ser seguida por todos os que escrevem textos que circulam nesse meio, exatamente o contrário do que a definição bakhtiniana permite concluir. Dessa forma, uma das motivações para o trabalho com gêneros aliado a uma teoria da subjetividade na linguagem é, precisamente, obviar a relatividade presente em todo e qualquer gênero, inclusive os tidos como mais "ortodoxos" 
pelos alunos. É parte de nossa função, como professores de texto, levar os alunos a perceberem que há lugar para a subjetividade em meio à objetividade, o que só pode ser feito centrando o estudo nas dimensões textuais da expressão oral e escrita, tal como preveem Dolz, Noverraz e Schneuwly (2004).

Todavia, ainda que estejamos em pleno acordo com a citação dos teóricos, reproduzida anteriormente, temos consciência de que infringimos o seu pensamento em pelo menos um aspecto: o estudo de um só gênero. A organização do ensino em sequências didáticas proposta pelos autores deixa claro, inclusive textualmente, que sua finalidade é de "ajudar o aluno a dominar melhor um gênero de texto, permitindo-lhe, assim, escrever ou falar de uma maneira mais adequada numa dada situação de comunicação (2004, p. 83, grifo dos autores). O que se observa, em contrapartida, é que os gêneros necessários à elaboração de um trabalho de conclusão de curso, de uma dissertação ou tese - produtos finais a serem produzidos pelos alunos que buscam o curso - não foram suficientemente desenvolvidos nos estágios anteriores de seu ensino, o que exige que sejam trabalhados em nosso programa. Ou seja, já partimos do pressuposto, como se pode observar, de que os gêneros do discurso são relativamente dependentes, ou, melhor, de que as habilidades necessárias à produção de determinados gêneros são igualmente exigidas na produção de outros, de forma mais elaborada e aliadas a outras habilidades. Vejamos um exemplo prático: para redigir um trabalho de conclusão de curso, o graduando precisa dominar as habilidades intrínsecas à produção de resumos, resenhas, relatórios, dissertações etc., mesmo que esses gêneros não sejam expressos como tais no trabalho final. Isto é, o que está em jogo, para nós, mais do que o ensino do que torna um gênero relativamente estável, nomeadamente, sua forma e sua função, é a capacidade de aprendizado das habilidades necessárias à produção de determinados gêneros, uma vez que estas serão os pilares para a produção de novos textos. Mais uma vez, estamos aqui diante da possibilidade de ensinar como produzir algo diferenciado com base na semelhança, como produzir algo particular partindo do universal, processo que constitui o centro dos estudos que tomam a linguagem como discurso, como língua em uso e sobre os quais nos apoiamos.

Com base em tais concepções, partilhadas com os alunos, organizamos o trabalho com os seguintes gêneros acadêmicos: resumo, resenha, ensaio, relatório, artigo científico, monografia e apresentações orais (em seminário de aula e em eventos). No caso de apoio a discentes da pós-graduação, acrescentamos os módulos dissertação e tese. Inspirados livremente na noção de sequência didática, podemos, de forma esquemática, representar a organização do curso da seguinte forma: 
Tendo em vista que cada módulo deve contribuir para uma produção final de qualidade, seja ela de um TCC, uma dissertação, tese ou até mesmo trabalhos de menor envergadura, a ordem dos gêneros trabalhados não é fortuita. Ela segue uma orientação de soma de conhecimentos e cumprimento de pré-requisitos. Assim, na produção diagnóstica, primeira parte da sequência didática, o trabalho realizado tem caráter basilar: são discutidas noções de texto porque, ao contrário do senso comum, o que se verifica na prática é que as características que configuram um texto enquanto tal não são claras para os alunos. Ora, entender o que faz de um texto um texto é essencial para o desenvolvimento de qualquer habilidade de escrita e de leitura. Nesse sentido, esse módulo privilegia aspectos não somente intratextuais, como coesão e coerência, como também aqueles que não se manifestam linguisticamente, mas que têm relação fundamental com a escrita: o contexto, o interlocutor e o suporte. Também são tratadas, nessa fase, as quatro qualidades fundamentais do bom texto, seguindo o postulado de Guedes (2009): unidade temática, questionamento, concretude e objetividade.

Uma vez socializado o entendimento do que é texto, passa-se, então, para o primeiro módulo (Resumo), no qual a grande tônica é a interpretação de texto e o uso de resumo como método de leitura. A primeira explica-se pelo fato de que somente quando se compreende bem um texto torna-se possível resumi-lo. $\mathrm{Ou}$ seja, o resumo é fruto de um entendimento tão eficaz que o leitor se mostra capaz de, com suas próprias palavras, reproduzir o que leu. A segunda ênfase tem inspiração nas palavras de Medeiros, ao salientar que "a interpretação é um processo num primeiro momento, de dizer o que o autor disse, parafraseando o texto, resumindo-o; é reproduzir as ideias do texto" Medeiros ( 2012, p. 89).

Como bem aponta o excerto acima reproduzido, trata-se, no estudo do resumo, de um primeiro momento no desenvolvimento da capacidade interpretativa do aluno. O segundo momento, mais elaborado, pressupõe o primeiro, mas vai além. No módulo "Resenha", os alunos aprendem a ler analisando, ou seja, a verificar dados e argumentos, o tom utilizado pelo autor, seu movimento argumentativo, enfim, todos os elementos que dizem respeito não só ao conteúdo do texto, ao enunciado, como também à sua forma de organização, a enunciação. Entendemos, ainda junto a Medeiros, que "análise é o fundamento para elaboração de reflexões que mostrem a organização dos elementos identificados no texto e 
seu aproveitamento reflexivo e argumentativo. Analisar significa, portanto, decompor, examinar sistematicamente os elementos que compõem o texto" (2012, p. 92). É precisamente essa capacidade de análise que se tenta desenvolver no módulo "Resenha".

A análise da organização do texto e, principalmente, dos argumentos que o compõem leva a um problema frequente: a seleção dos dados. Isso se verifica já nas produções de resumo, quando muitos alunos verbalizam extrema dificuldade de selecionar apenas os elementos principais de um texto. A fim de trabalhar essa percepção, que diz respeito, essencialmente, à relação das partes com 0 todo, o módulo "Relatório" tem por ofício promover um experimento de distanciamento do texto, pois somente por meio desse movimento é possível olhar para os dados e selecionar o que é relevante ou não. Destarte, esse módulo enfatiza, por meio do distanciamento, a seleção de dados e argumentos e a forma de escrita com base em um leitor-alvo específico, o que fica muito evidente na elaboração de relatórios: há relatos mais ricos em detalhes e outros menos, sempre em virtude do conhecimento de quem é o interlocutor real ou em potencial.

O distanciamento e a objetividade próprios do relatório são quebrados, propositalmente, pelo módulo "Ensaio", no qual os alunos são levados a refletir sobre questões de subjetividade, autoria e originalidade. É interessante a observação de que, por ser um gênero com menor rigor formal, muitos alunos, ainda sob efeito da noção de gênero como molde, têm dificuldade na composição. O que se procura desenvolver nesse estágio, mais do que o desenvolvimento de habilidades que farão dos alunos ensaístas de qualidade, é a percepção de que os gêneros são maleáveis e de que nenhum texto é unânime. Isto é, nenhum texto agrada a todos ou é visto por todo tipo de leitor como uma boa produção. Entretanto, há algo que, independentemente do gosto do leitor, é indiscutível: a capacidade do autor de se posicionar de forma clara e original sobre determinado assunto.

Todas essas habilidades coadunam-se no módulo "Artigo", de especial interesse para a maioria dos discentes. Aqui, o interesse recai, majoritariamente, na análise do movimento argumentativo inerente aos textos que apresentam como dominante sequencial o tipo argumentativo (cf. MARCUSCHI, 2002). Assim, enfatiza-se a análise da progressão lógica dos argumentos, a verificação de falácias e a antecipação de possíveis argumentos contrários como estratégias de produção de textos que privilegiam a argumentação.

O último módulo, "Dissertação e tese", é, também, o ponto de chegada da sequência didática, ou melhor, daquilo que, em sentido lato, assim chamamos. Evidentemente, não se espera que os alunos terminem o curso produzindo tais trabalhos, mas, pelo menos, sendo capazes de reconhecer as habilidades necessárias para compô-los. Ou seja, a 
produção final é resultado do acúmulo de conhecimentos trabalhados ao longo de diferentes gêneros, cada qual demandando de quem escreve habilidades específicas que, quando bem desenvolvidas, contribuem para a produção de bons trabalhos finais.

De todo o exposto, observamos que a organização do curso alia sempre leitura e escrita, ambas contempladas não somente em sua forma como também - e principalmente - em seu sentido. Por adotar que forma e sentido estão entrelaçados na leitura e na escrita e que os gêneros, conforme Bakhtin (1979/2003), organizam-se em torno do tema - objeto do discurso/ideia do autor, da construção composicional -, procedimentos de organização, disposição e acabamento do enunciado/discurso, e do estilo - seleção de recursos do léxico, fraseológicos e gramaticais da língua para exprimir a posição valorativa do falante -, o projeto-ação aqui descrito e direcionado ao público universitário sustenta-se no seguinte eixo metodológico:

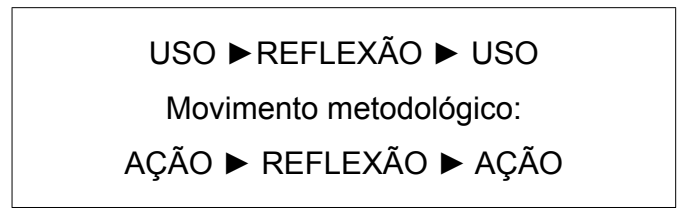

Esse eixo metodológico desenvolve-se em um trabalho que considera os usos da língua e as habilidades vinculadas a esses usos como relacionadas à reflexão do funcionamento da língua. Nesse caso, questões de estrutura dos gêneros e o estilo são tratados com a consideração da gramática como o lugar que comporta as formas que possibilitam a produção de sentidos no discurso. Por isso, os eixos estruturadores de cada módulo sustentam-se da seguinte maneira:

\begin{tabular}{|c|c|}
\hline $\begin{array}{l}\text { Leitura } \\
\begin{array}{c}\text { Exploração, na leitura de textos, das pistas } \\
\text { direcionadoras do sentido. }\end{array}\end{array}$ & $\begin{array}{c}\text { Escrita } \\
\Rightarrow \text { Prática de produção de textos que envolve } \\
\text { escrita, análise e reescrita. }\end{array}$ \\
\hline \} $\begin{array}{r}\text { Análise e reflexã } \\
\text { REFLEXÃO: prática }\end{array}$ & de análise linguística \\
\hline $\begin{array}{r}\text { A gramática da língua em } \\
\text { A gramática como um meio para o desenvolvim } \\
\text { escuta, de leitura, de prc }\end{array}$ & $\begin{array}{l}\text { so e a organização textual; } \\
\text { ento da competência discursiva (habilidades de } \\
\text { dução oral e de escrita). }\end{array}$ \\
\hline
\end{tabular}

Com esses eixos metodológicos e estruturadores, o trabalho em cada módulo é desenvolvido como representado na sequência a seguir: 


\section{Leitura de textos do gênero a ser trabalhado}

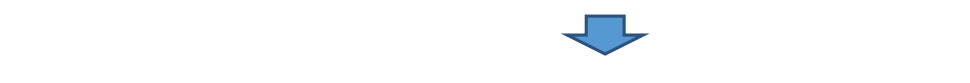

Caracterização do gênero: tema, estrutura composicional e funcionamento linguístico (noções teóricas)

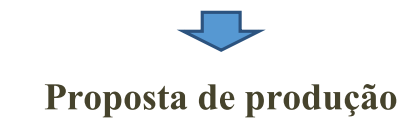

Escrita do texto

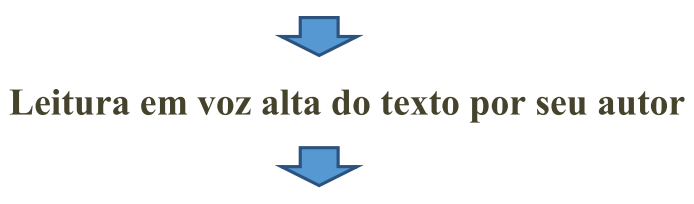

Análise do texto pelos colegas e professores (aspectos ligados à interlocução, ao conteúdo e à estrutura)

\section{Possibilidade de reescrita}

Avaliação do texto lido pelos professores de acordo com uma planilha, que considera aspectos de interlocução, de conteúdo, de estrutura e de funcionamento linguístico;

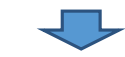

\section{Reescrita}

Com o esboço dessa sequencialização, didáticas “menores”, em cada um dos torna-se possível perceber que, dentro módulos, que podem ser ilustradas da da sequência didática maior, esquema- forma que segue: tizada anteriormente, tem-se sequências
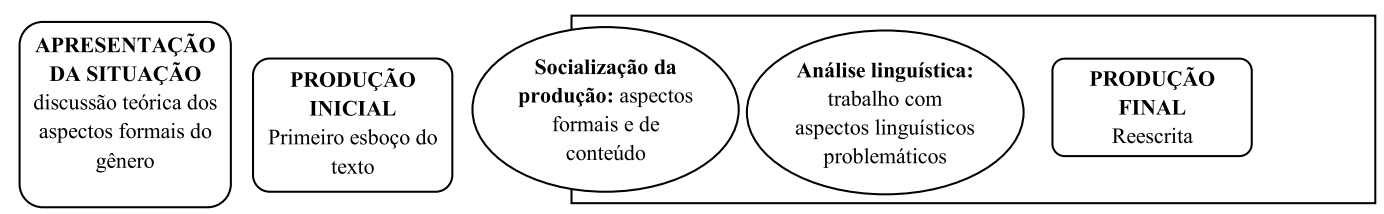


\section{Conclusão: finalizando a reflexão}

Neste texto, tentamos mostrar um modo possível de viabilizar um trabalho, no contexto universitário, que considere o diálogo entre discursos e entre interlocutores como elemento norteador de uma proposta que procura expor os alunos a situações de aprendizado significativas em que a reflexão acerca dos conteúdos textuais e gramaticais esteja atrelada aos usos e às demandas exigidas pelas atividades acadêmicas.

Por fim, nunca é demais lembrar, a proposta aqui apresentada figura apenas como uma das inúmeras maneiras possíveis de se trabalhar com texto em sala de aula e de desenvolver as habilidades de leitura e de escrita. O importante, acreditamos, é que, qualquer que seja a escolha metodológica do professor, esta precisa, necessariamente, estar alinhada com seus pressupostos teóricos, alinhamento que tencionamos expor com este texto e com o exemplo do trabalho que temos desenvolvido ao longo dos últimos anos com nossos alunos de graduação e de pós-graduação.
Courses organized by modules: a proposal for the development of reading and writing skills in higher education

\section{Abstract}

The objective of this text is to reflect on an alternative to the teaching of reading and writing in undergraduate education through a course organized in modules, in which different discourse genres and dealt with in order to contribute to the development and consolidation of the abilities necessary to the production of texts in the academic context. The work also aims at supplying, although partially, the gap, in terms of scientific production, of works that take the teaching of text and Portuguese language in undergraduate level as an object of study.

Keywords: Text. Undergraduate teaching. Modules. Discourse genres.

\section{Notas}

1 O Projeto de Língua Portuguesa, coordenado pela Professora Drª . Carmem Luci da Costa Silva, é formado por uma equipe de bolsistas Capes-Reuni de Pós-Graduação, que atuam como docentes, e monitores de graduação, que assessoram as atividades. Em 2010, atuaram no projeto as bolsistas da pós-graduação Lia Cremonese (doutoranda), Carolina Knack (mestranda) e Aline Juchem (mestranda), juntamente com os monitores da graduação Maurício Sortica, Rodrigo Mendonça, Lizbeth Volker e Arthur Telló. Em 2011, compuseram a equipe as mestrandas Carolina Knack, Gabriela Barboza, Verônica Machado e Luana Lima; as doutorandas Paula Nunes e Lia Crermonese e a pós-doutoranda Claudia Toldo, juntamente com os monitores Maurício Sortica (2011/1), Marcelo Maciel (2011/1), André Bernhard (2011/1 e 2011/2), Maria Eduarda Tabajara 
(2011/1-2011/2), Dafne Helena Rosa (2011/2) e Michel Flores (2011/2). Em 2012, a equipe foi composta pelas mestrandas Gabriela Barboza, Verônica Machado, Luana Lima e Bruna Sommer; as doutorandas Paula Nunes (até maio/2012), Lia Cremonese e a pós-doutoranda Claudia Toldo (até set./2012). Em junho de 2012, passou a compor a equipe a doutoranda Simone Barros, e Paula Nunes retornou como bolsista de pós-doutorado, atuando de setembro a dezembro de 2012. Em 2012, o projeto contou com os seguintes monitores de graduação: Maria Eduarda Tabajara (2012/1), Aline Costa (2012/1 e 2012/2), Juliana Paz (2012/1 e 2012/2) e Renata Ferreira (2012/2).

\section{Referências}

ADAM, Jean-Michel. A linguística textual: introdução à análise textual dos discursos. São Paulo: Cortez, 2008.

BAKHTIN, Mikhail. Os gêneros do discurso. In:__ (1979). Estética da criação verbal. São Paulo: Martins Fontes, 1992.

BENVENISTE, Émile. (1966) Problemas de linguística geral I. Campinas, SP: Pontes Editores, 1995.

. (1974). Problemas de linguística geral II. 2. ed. Campinas, SP: Pontes Editores, 1989.

BRASIL. Secretaria de Educação Média e Tecnológica. Parâmetros Curriculares $\mathrm{Na}$ cionais: ensino médio - língua portuguesa. Brasília: MEC; SEMTEC, 2002.

DOLZ, Joaquim; NOVERRAZ, Michèle; SCHNEUWLY, Bernard. Sequências didáticas para o oral e a escrita: apresentação de um procedimento. In: SCHNEUWLY, B.; DOLZ, J. Gêneros orais e escritos na escola. (As faces da linguística aplicada). Trad. de Roxane Rojo e Glais Sales Cordeiro. Campinas, SP: Mercado de Letras, 2004.

DUCROT, Oswald. Princípios de semântica linguística: dizer e não dizer. São Paulo: Cultrix, 1972.
GUEDES, Paulo Coimbra. Da redação à produção textual: o ensino da escrita. São Paulo: Parábola Editorial, 2009.

MARCUSCHI, Luís Antônio. Gêneros textuais: definição e funcionalidade. In: DIONÍSIO, Anna Rachel Machado; BEZERRA, Maria Auxiliadora. Gêneros textuais e ensino. 2. ed. Rio de Janeiro: Lucerna, 2002.

MEDEIROS, João Bosco. Redação científica: a prática de fichamentos, resumos, resenhas. 11. ed. 5. reimpr. São Paulo: Atlas, 2012.

MOTTA-ROTH, Desirée; HENDGES, Graciela Rabuske. Produção textual na universidade. São Paulo: Parábola Editorial, 2010. 